\title{
Factors underlying to increased prevalence of Pythium disease following non-targeted fungicide application to corn seeds
}

\author{
Huizhu Yuan ${ }^{1}$, Xiujun Tang ${ }^{1}$, Shuning Chen ${ }^{1}$, Xiaojing Yan ${ }^{1}$, Zhenying Wang ${ }^{1}$, and Daibin \\ Yang $^{1}$
}

${ }^{1}$ Chinese Academy of Agricultural Sciences Institute of Plant Protection

September 11, 2020

\begin{abstract}
Microbial communities are essential for soil health, but fungicide application can have major effects on their structure, and it is difficult to predict whether non-target pathogens in the soil will cause major crop damage. Using collected soil with a history of poor corn (Zea mays) seedling emergence, we demonstrate that the poor emergence of corn seedlings from seeds coated with the fungicide tebuconazole is primarily due to infection of surviving soil pathogens, particularly Pythium complexes that are not targeted by fungicide tebuconazole. We determined that the bases for the increased infection by non-target species of Pythium were: 1) the selective fungicidal activity of seed-applied tebuconazole showed a low level of control against Pythium species but had a significant effect on soil fungi, thereby releasing Pythium spp. from competition with other soil microorganisms; 2) the growth of the natural enemies in soil, Trichoderma spp., was strongly inhibited by tebuconazole; and 3) low temperature was the key factor of triggering fatal injury of Pythium pathogens to corn seeds. Taken together, the non-target effects of tebuconazole are likely not significant under favorable plant growing conditions, but are considerable as a result of low temperature stress.
\end{abstract}

\section{Hosted file}

Manuscript.docx available at https://authorea.com/users/355746/articles/480561-factorsunderlying-to-increased-prevalence-of-pythium-disease-following-non-targeted-fungicideapplication-to-corn-seeds 